\title{
HISTÓRIAS DE OUTUBRO: TROTSKI E A REVOLUÇÃO RUSSA
}

\author{
Fábio José de Queiroz ${ }^{1}$ \\ Frederico Jorge Ferreira Costa ${ }^{2}$
}

\begin{abstract}
Resumo:
A revolução está presente. Outubro resiste em suas personagens, em seus fatos e, também, nos escritos que a retomam e a imortalizam. Há personagens que se confundem com os fatos e a escrita a respeito da Revolução de Outubro na Rússia. Leon Trotski a viveu como personagem e historiador. Neste artigo analisamos o papel desempenhado por Trotski na Revolução de Outubro tomando como referência não somente sua ação militante durante os acontecimentos de 1917, mas, do mesmo modo, seu subsídio teórico marxista a esse importante movimento revolucionário do século XX. Baseados nessa reflexão de Trotski, e no conjunto de seus acertos teórico-políticos, concluímos que ele ainda tem algo a dizer aos movimentos anticapitalistas do século XXI.
\end{abstract}

Palavras-chave: Trotski; Revolução de Outubro; Militância; História.

\section{STORIES OF OCTOBER: TROTSKI AND THE RUSSIAN REVOLUTION}

\begin{abstract}
:
The Revolution is present. October resists in its personages, in its facts and also in the writings that take it back and immortalize it. There are personages who are confused with the facts and the writing about the October Revolution in Russia. Leon Trotsky lived it as a personage and a historian. In this article we analyze the role played by Leon Trotski in the October Revolution in Russia, taking as a reference not only to its militant action during the events of 1917, but, even so, his allowance theoretical marxist of this important revolutionary movement of the 20th century. Based on this reflection of Trotsky, and in the set of his theoretical-political correctness, we conclude that it still has something to say to the anti-capitalist movements of the 21 st century.
\end{abstract}

Keywords: Trotski; October Revolution; Militancy; History.

\section{Introdução}

A revolução está presente. Outubro é rememorado em suas personagens, em seus fatos e, também, nos escritos que a retomam e a imortalizam. Há personagens que se destacam, caso de Leon Trotski ${ }^{3}$ (1879-1940), ele a viveu como personagem e historiador. Em todos os momentos do processo revolucionário russo Trotski esteve no centro dos acontecimentos: presidente do soviete (conselho operário) nas revoluções de 1905 e 1917; dirigente do Comitê

1 Doutor em Sociologia (UFC), Professor do Departamento de História da Universidade Regional do Cariri (URCA) e do Mestrado Profissional em Ensino de História (ProfHistória), com Pós-Doutoramento em Educação pela Universidade Federal do Ceará (UFC). É coordenador do grupo de pesquisa Marx, Classes Sociais, Ideologia, Estado e Revolução. E-mail: fabioqueirozurca@ gmail.com

2 Doutor em Educação. Professor da Faculdade de Educação de Itapipoca da Universidade Estadual do Ceará (FACEDI/UECE). Pesquisador colaborador do Instituto de Estudos e Pesquisas do Movimento Operário (IMO). Membro do Programa de Pós-graduação em Educação (PPGE/UECE) e do Mestrado Acadêmico em Serviço Social, Trabalho e Questão Social (MASS/UECE). Coordenador do Grupo de Pesquisas Ontologia do Ser Social, História, Educação e Emancipação Humana (GPOSSHE). E-mail: frederico.costa@ uece.br

3 Codinome de Lev Davidovich Bronstein. 
Militar Revolucionário do soviete, que organizou a insurreição de outubro de 1917; dirigente do Exército Vermelho durante a guerra civil e a intervenção externa; responsável pela reconstrução do sistema de transportes e comunicações e, principal opositor a Stálin, expressão da degeneração burocrática, no partido e na URSS. À vista disso, nos apoiamos nessa constatação para examinar as relações de Trotski com a Revolução de Outubro.

Trotski não apenas se revelou como um dos líderes de Outubro, mas, também, se destacou como um dos historiadores da revolução. Nele, ação e ciência histórica se aliam de modo admirável. Essa fusão do militante e do historiador seria suficiente, quem sabe, para validar a opção com a qual resolvemos trabalhar neste estudo. Ademais, o fato de ele haver sofrido uma sórdida campanha de desqualificação político-histórica, encabeçada pela burocracia soviética, incorpora outro elemento não desprezível a justificar essa inclinação teórica.

Desse modo, nosso alvo é o estudo dos nexos de Trotski com a Revolução de Outubro de 1917, na Rússia, considerando o papel por ele desempenhado nos acontecimentos, bem como a análise que empreendeu acerca do processo revolucionário. Por outro lado, com o intuito de proporcionar maior rigor ao trabalho de pesquisa histórica, optamos por recorrer às conclusões de outros autores acerca da revolução e do papel histórico de Trotski, notadamente de inferências de Rosa Luxemburgo, John Reed, Pierre Broué e Victor Serge, elegendo, deliberadamente, interpretações mais clássicas como apoio às soluções teóricas pessoais que tecemos ao longo deste artigo.

\section{Trotski ou o outubro de um homem}

Como já sugerido, Trotski viveu a Revolução de Outubro duas vezes: primeiro, no papel de líder dessa epopeia do século XX; depois, como historiador - um dos "memoriadores" - de uma narrativa épica cujas repercussões ainda hoje são objetos de reflexão. A análise de Trotski está contida sobremaneira na monumental obra História da revolução russa, um livro, ao mesmo tempo, extenso, com mais de 1000 páginas, e intenso, pela recuperação e reconstituição dos fatos tendo como substrato as análises de um dos protagonistas dos acontecimentos.

Sabe-se que Trotsky retorna do exílio em maio de 1917, quando o czarismo havia caído como resultado do triunfo da Revolução de Fevereiro. Trata-se de um processo insurrecional que modifica as instituições políticas sem tocar nos fundamentos econômicos nos

\begin{tabular}{|l|l|l|l|l|}
\cline { 2 - 5 } & Ano 8 & n. 14 & Janeiro - Julho 2019 & p. $264-277$ \\
\hline
\end{tabular}


quais repousa a sociedade. Nesse momento, o país é administrado pelo governo provisório, formado de representantes de distintos partidos, a começar dos socialistas até os democratas burgueses mais típicos, sem nos esquecer de sobras políticas do antigo regime que insistiam em sobreviver.

Nesse instante, o partido bolchevique está permeado de contradições que o dilaceram. Lênin havia voltado do exílio e, em pouco tempo, travado uma luta contra a maioria da direção do partido na qual se faz vitorioso. A tática leninista se impõe como tática dos bolcheviques. Nesse rearmamento do partido não há espaço para apoio ao governo provisório - um apanhado mal-ajambrado de representantes da burguesia e do proletariado: "Nenhum apoio ao Governo Provisório, explicar a completa falsidade de todas as suas promessas" (LÉNINE, 1978, p. 14).

Lênin rompe com a ideia de uma longa etapa de transição que se estende da vitória da revolução política até o triunfo do proletariado. Nisso, ele se aproxima do conteúdo essencial da teoria da revolução permanente associada ao nome de Trotski. Este, evidentemente, não pertencia aos círculos bolcheviques. Era dirigente de um grupo denominado interdistrital. Quando essas mudanças se operam no âmbito da linha estratégica leninista, progressivamente, os dois agrupamentos se aproximam, e em pouco tempo, o grupo interdistrital adere ao partido de Lênin, Zinoviev e Kamenev.

Da parte de Trotski ocorre uma mudança que não deve ser menosprezada. Depois de longos anos de desconfiança com relação ao modelo de partido leninista, ele reavalia seu ponto de vista anterior, e desde então, segundo Lênin, não houve ninguém mais bolchevique do que o dirigente da ex-interdistrital. De imediato, Leon Trotski é alçado ao Comitê Central (CC) bolchevique e, como membro desse organismo, participa de toda elaboração da tática que finda com a derrubada do governo provisório e a vitória da revolução proletária.

Anos depois, com a degeneração política do primeiro Estado operário vitorioso ${ }^{4}$, obtém peso e volume a campanha de difamação contra Trotski, que começa na cúpula do aparelho estatal soviético e se espalha pelo Partido Comunista da URSS, pela III Internacional, pela mídia e por milhões de fios que ligam as necessidades da burocracia aos meios mais rápidos de veiculação de anúncios, comunicados e exortações. Em uma célebre biografia de Lênin,

\footnotetext{
4 Trotski imortalizou a categoria de Estado Operário para a ex-URSS, acrescentando-lhe a designação de degenerado ou burocratizado. Não se tratava mais de um Estado capitalista, mas de um Estado de transição, que tanto poderia recuar como avançar. A história assinalou o seu brutal recuo.

\begin{tabular}{|l|c|c|c|c|}
\hline Rovita Dialectus & Ano 8 & n. 14 & Janeiro - Julho 2019 & p. $264-277$ \\
\hline
\end{tabular}
}


preparada por um coletivo de autores do Instituto de Marxismo-Leninismo, ligado ao CC do PCUS, lê-se:

\begin{abstract}
Mas Trotski tomou uma posição perigosa para os destinos da revolução. Sem se pronunciar abertamente contra a resolução do CC acerca da insurreição armada, continuou a semear ilusões constitucionais dentro do partido, insistindo no adiamento da insurreição até à realização do II Congresso dos Sovietes, o que de fato significava torpedear a insurreição. (Instituto de Marxismo-Leninismo anexo ao CC do PCUS, 1984, p. 285).
\end{abstract}

Eis uma iniciativa exemplar de se torpedear a imagem de uma liderança revolucionária, apresentando-a como hesitante, às vésperas da tomada do poder. Toma-se uma mediação tática, proposta por Trotski, como demonstração de suas "ilusões constitucionais". O que ele indicava é que não deveria se descartar a hipótese de que a tomada do poder pudesse se dar formalmente pelas mãos de uma organização soviética. A esse respeito, ele se pronuncia:

Assim, se bem que quiséssemos fazer coincidir a tomada do poder com o $2^{\circ}$ Congresso dos Sovietes, de modo nenhum tivemos a esperança ingênua de que este, por si só, pudesse resolver a questão do poder. Este fetichismo da forma soviética era-nos completamente alheio. (TROTSKI, 1979, p. 70).

Como se percebe nessa passagem, nada tão distante da tática de Trotski do que "uma posição perigosa para os destinos da revolução" na qual ele, por suposto, continuasse "a semear ilusões constitucionalistas". Não por acaso, a passagem do poder do domínio do governo provisório para as mãos de um novo governo, hegemonizado pela fração bolchevique, deu-se pela intermediação do Comitê Militar Revolucionário, no espírito da tática de Trotski, que, naquilo que havia nela de mais essencial, coincidia com a tática de Lênin. Do contrário, por que este haveria de concordar com a indicação de Trotski como uma das principais lideranças, senão a principal, da insurreição de outubro, considerando não somente a "posição perigosa para os destinos da revolução" que decorreria de sua tática, mas, também, de suas "ilusões constitucionalistas"?

Essa discussão, indevidamente engendrada e nutrida pelo stalinismo, grosso modo, reaparece, de maneira eventual, não apenas nos velhos manuais de história que repõem antigas controvérsias do campo da esquerda, mas até em celeumas mais recentes, notadamente quando se reabilita o dualismo entre a excelência e a justeza de Lênin em oposição às hesitações de Trotski. A história demonstra à exaustão o lugar do indivíduo na história, e a historiografia da Revolução Russa, amiúde, ratifica a importância de Lênin para que as coisas se dessem da maneira que se deram e não de outras maneiras quaisquer. Nisso parece não haver indício para, seja qual for a polêmica, alguma discussão mais séria se instaurar. Trata-se, no entanto, de algo

\begin{tabular}{|l|l|l|l|l|}
\cline { 2 - 5 } & Ano 8 & n. 14 & Janeiro - Julho 2019 & p. $264-277$ \\
\hline
\end{tabular}


distinto de uma atitude de venerar a Lênin e amaldiçoar a Trotski. Um estudo rigoroso da história não admite esse tipo de ilação. Ou, pelo menos, não deveria.

Rosa Luxemburgo, contemporânea dos dois revolucionários, acolheu a ideia da importância que esses dois homens adquiriram no processo que se estende da preparação ao triunfo da Revolução de Outubro, coroando o que ela nomeia de ofato mais marcante da guerra mundial. Quanto a isso, a marxista polonesa parece não ter dúvida. Aliás, para ela, "também não há dúvida de que as cabeças inteligentes que dirigem a Revolução Russa", não são outras senão as de Lênin e Trotski (Luxemburgo, 2011, p. 179).

Por que Rosa situaria Lênin e Trotski no mesmo plano histórico? Pensamos que a história das divergências de Lênin e Trotski nem sempre pode ser entendida como a dos erros do segundo e a dos acertos do primeiro. Essa história como mistificação não parece se fiar em um bom método marxista. Por isso, a atitude cuidadosa de Rosa Luxemburgo não tem qualquer relação com as falsificações stalinistas que ora tentaram apagar a imagem de Trotski do imaginário revolucionário, ora buscaram deformar seu retrato histórico. Os erros de Trotski são humanos e característicos de um homem de ação, e esse aspecto da questão não deveria ser empregado seja para removê-lo do tablado histórico, seja para deturpar seu papel nos acontecimentos.

Nesse sentido, a leitura de um livro escrito não apenas por um autor não russo, mas redigido no calor dos acontecimentos, ajuda de vez a escudar Trotski não apenas do fogo cerrado de seus inimigos, mas, também, do fogo amigo daqueles que, em certos casos, se apresentam como "trotskistas". Trata-se do livro "Dez dias que abalaram o mundo", do jornalista estadunidense John Reed. Ele viveu os dias decisivos que constituíram o prólogo, os fatos fundamentais e os dias posteriores da Revolução de Outubro. Reed informa ao leitor, por exemplo, que "Em nome do Comitê Militar Revolucionário, Trotski declarou que o Governo Provisório não existia mais" (REED, 2002, p. 131). Como entregar nas mãos de um homem com posições perigosas para revolução, tarefa tão determinante para os destinos dessa mesma revolução?

Aliás, como tomar o revolucionário ucraniano na condição de quase um conciliador com a ordem existente, permeado de ilusões constitucionais, quando ele sobe a tribuna - em nome dos comunistas-bolcheviques - para afirmar que "Coalizão nem sempre quer dizer força" (REED, 2002, p. 195) ou bramir perante os membros da duma: "Vós não sois mais os representantes do povo" (REED, 2002, p. 167). Eis o papel cumprindo por Trotski nos acontecimentos cruciais que definem a dinâmica da revolução! Aliás, é ele como presidente do

\begin{tabular}{|l|c|c|c|c|}
\cline { 2 - 5 } Q Dovista & Ano 8 & n. 14 & Janeiro - Julho 2019 & p. $264-277$ \\
\hline
\end{tabular}


Soviet de Operários e Soldados que, junto com o presidente do Comitê Militar Revolucionário, assina a ordem para "armar os operários com todas as armas disponíveis" e "observar a mais rigorosa disciplina e estar postos para apoiar por todos os meios o exército da revolução" (REED, 2012, p. 235). ${ }^{5}$

Com o desfecho da insurreição praticamente definido, Trotski se dirige ao PréParlamento e de lá anuncia que o velho poder está morto. É hora de o novo poder se erigir. Com referência a esse episódio, o testemunho de um contemporâneo desse episódio é indicativo da participação decisiva de Leon Trotski nos dias que corriam e nas deliberações que lhes ditavam um rosto:

Trotski acabara de provocar, na tribuna do pré-parlamento, a retirada dos bolcheviques da assembleia. Sua voz metálica tinha lançado à mais alta autoridade da república o desafio dos proletários e dos camponeses. (SERGE, 2007, p. 73)

Eis o retrato de um homem que, longe de vacilar ante suas tarefas, as cumpria com desassombro. $\mathrm{O}$ mito stalinista de um Trotski que quase fugia ao outubro que lhe desafiava parece mais uma anedota acanhada do que uma hipótese que devesse ser levada a sério. Paradoxalmente, esse espírito estreito ainda alimenta as imaginações pouco precavidas. As conexões de Reed e Serge com os acontecimentos de 1917 ajudam a desfazer parte expressiva da mitologia que se construiu ao redor da participação de Trotski no momento mais decisivo do século XX.

De qualquer modo, pode ocorrer de o leitor mais exigente contra-argumentar que essas ações são públicas e refletem unicamente a obediência de Trotski às decisões do Comitê Central bolchevique e não necessariamente o resultado de suas convicções pessoais. Outra vez, Reed nos fornece elementos mais do que razoáveis no que diz respeito à coerência entre as decisões do partido e a consciência de Davidovitch como teórico marxista e militante revolucionário. Aqui, é preciso pôr em evidência o fato de que, talvez, nenhum estrangeiro adentrou tão profundamente o coração dos acontecimentos como John Reed. Para ele, franquearam-se as portas da revolução, desde a superfície dos episódios até a vida interna da

5 O papel de Trotski, no momento da insurreição e instalação do governo revolucionário, é de tal modo proeminente que a própria nomenclatura de "comissários do povo", usada para designar as funções dos novos membros governamentais, segundo Broué, é proposta por ele e "apoiada com entusiasmo por Lênin". Nos detalhes mais simples se recupera o lugar privilegiado que Trotski ocupou nos acontecimentos de 1917. O rechaço à participação dos bolcheviques no pré-parlamento, cujo papel é obstruir o curso da insurreição em movimento, é encabeçado por Trotski, o que, uma vez mais, descontrói a hipótese de sua rendição ao legalismo democrático-burguês. A esse respeito, Lênin é categórico: "Trotski era partidário do boicote. Bravo, camarada Trotski! (...) Viva o boicote!" (BROUÉ, Pierre. O partido bolchevique, São Paulo: Sundermann, 2014, p. 94).

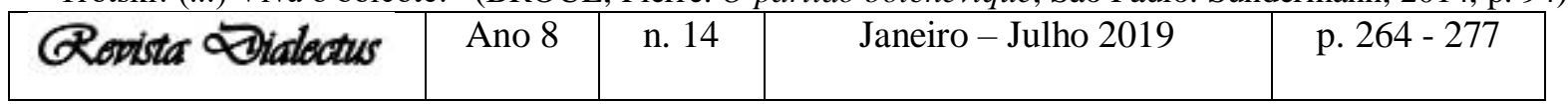


organização bolchevique. Ele conviveu com os líderes revolucionários, mediu a pulsação de cada um deles e arrancou informações que inteiraram o mundo a respeito do fato mais colossal nascido do ventre da Primeira Guerra Mundial. Nem o que se passava no âmbito da direção máxima do partido bolchevique lhe era estranho:

Mas o Comitê Central do Partido Comunista estudava a insurreição. Passou a noite do dia 23 reunido. Estavam presentes todos os intelectuais do partido, os dirigentes e os delegados dos operários e da guarnição de Petrogrado. Entre os intelectuais, só Lênin e Trotski estavam pela insurreição. (REED, 2002, p. 78).

"Entre os intelectuais, só Lênin e Trotski estavam pela insurreição”. A força dessa frase coincide com as apreciações históricas que, posteriormente, Trotski faria com relação ao seu papel nos acontecimentos de 1917. Há uma coerência entre os relatos e as análises de Reed e Trotski. Logo, o autor de História da revolução russa não engendrou uma história na qual se autoglorificava. A propósito, essa não é a única passagem do livro do jornalista em que a firme atitude de Trotski é ressaltada. Além de adotar uma posição vigorosa nos dias que precederam à organização da insurreição, nos dias que se seguiram ao triunfo da ação insurrecional, ele não deixou de crer - assim como Lênin - de que era possível assegurar o poder arrancado das mãos da burguesia. John Reed descreve essa convicção nos seguintes termos: "Excetuando Lênin, Trotski, os operários de Petrogrado e os soldados, ninguém acreditava que os bolcheviques poderiam manter-se no poder por mais de três dias". (REED, 2002, p. 166).

Em vista disso, é pouco consistente o empenho em menosprezar a conduta de Leon Trotski ao longo do processo revolucionário de 1917. Ao contrário de claudicação, a sua atitude é categórica, peremptória. Historicamente, os ventos que pretendem derrubá-lo nos parecem frágeis. Sopram e depois se desviam quase envergonhados de sua delicada vulnerabilidade.

\section{Trotski como analista de Outubro}

Na obra As lições de abril, Leon Trotski constata o que, para ele, seria um problema não desprezível, qual seja:

Se é verdade que na revolução de Outubro tivemos sorte, outro tanto não se poderá dizer do seu lugar na nossa literatura. Ainda não dispomos de uma única obra que dê um quadro geral da revolução de Outubro, fazendo sobressair os seus principais momentos de ponto de vista político e organizativo. (TROTSKI, 1979, p. 7).

\begin{tabular}{|l|l|l|l|l|}
\cline { 2 - 5 } & Ano 8 & n. 14 & Janeiro - Julho 2019 & p. $264-277$ \\
\hline
\end{tabular}


Para ele, Outubro é uma experiência que tem a nos ensinar. Esse é o seu pressuposto básico. Nasce daí a sua compreensão de que é necessário estudá-la. O livro As lições de outubro é produto direto dessa linha de raciocínio. Ademais, as deformidades do regime burocrático e a sua negligência com a ideia de verdade como regra de ouro dos que escrevem a respeito da história, sem dúvida, o induziram a se deter meticulosamente sobre os fatos que marcaram o ano de 1917 na Rússia. Decorre desse esforço a monumental obra História da revolução russa, elogiada inclusive por historiadores muitos comprometidos com seu ofício, dentre eles, Perry Anderson.

Neste artigo, não tomaremos como referência o amplo arco de obras de Trotski no qual a temática da Revolução de Outubro está inserida. Partiremos, fundamentalmente, dos dois livros antes citados: As lições de outubro e História da revolução russa. Nestas duas obras estão compiladas as principais conclusões de Leon Trotski com relação ao significado da revolução liderada pelos bolcheviques. Nos limites deste trabalho, elas nos parecem mais do que suficientes com vistas a oferecer ao leitor a visão histórico-teórica do autor a respeito de acontecimentos que, ainda hoje, dividem águas no campo da esquerda. Com a passagem recente do centenário da revolução, as polêmicas não tendem a sair de cena, mas, inversamente, devem ocupar os seus lugares no amplo tablado que se liga ao balanço desse notável acontecimento. As ideias de Trotski, no que diz respeito a Outubro, são partes indivociáveis de querelas históricas que cobram também seu lugar no debate. Portanto, vamos ao debate e às questões que ele suscita.

De Plano, uma conclusão teórico-histórica sobressai das páginas de As lições de outubro. Ela diz respeito aos vínculos da revolução com a guerra. Sobre isso, Trotski esclarece:

Precisamente por não ter dado lugar a uma pressão reformista, a guerra criara uma situação revolucionária. Das duas uma: ou se seguia a burguesia até o fim, ou então levantavam-se as massas contra ela, arrancando-lhe o poder. (TROTSKI, 1979, p. 29).

Trotski entende que um partido marxista, e os bolcheviques constituíam um partido marxista, não renuncia as reformas, entendendo que estas se referem sempre a questões secundárias. No caso da guerra, a burguesia jogava a sua sorte como classe dominante, e a questão do poder estava posta nitidamente. Quando essa questão está posta não há lugar para reformas. Em 1917, não havia espaço para reformas nem na Rússia dos czares nem na Rússia dos Kerenskins. A situação revolucionária que se abriu - decorrente da aceleração da luta de classes - colocou o problema do poder de modo cristalino. O fracasso de mencheviques e de socialistas revolucionários se fundamentava precisamente na ausência de possibilidades de uma

\begin{tabular}{|c|c|c|c|c|}
\cline { 2 - 4 } & Ano 8 & n. 14 & Janeiro - Julho 2019 & p. $264-277$ \\
\hline
\end{tabular}




\section{HISTÓRIAS DE OUTUBRO: TROTSKI E A REVOLUCÃO RUSSA}

Fábio José de Queiroz / Frederico Jorge Ferreira Costa

solução reformista para crise aberta com a guerra. O êxito bolchevique começa com o retorno de Lênin e com a mudança que ele imprime à orientação dos bolcheviques. Até então, a fração bolchevique trabalhava com um cenário em que a realidade se expressava mediante um processo lento e arrastado de aprofundamento da democracia (produto da Revolução de Fevereiro). É Lênin que se impõe contra essa "fórmula decorada" e levanta como tarefa a preparação para conquista do poder. Essa mudança de linha estratégica é o alicerce no qual se apoia o partido para, meses depois, organizar a insurreição vitoriosa. Essa parece a Trotski uma das principais lições que explicam o desenlace de outubro.

O que essa questão, efetivamente, demonstra é que: (1) A situação objetiva não pode ser desprezada. Não é possível que a revolução triunfe sem que antes disso se imponha uma situação revolucionária. A guerra e os seus desdobramentos estão na base da eclosão da situação revolucionária, mas essa não conduz, necessariamente, ao triunfo da revolução. (2) A começar daí decorre o aspecto subjetivo de todo processo. A existência do partido bolchevique e como ele foi sendo temperado nas situações mais difíceis da luta de classes, em última hipótese, desempenharam papel não ínfimo no processo revolucionário. Acontece que esse partido não nasceu pronto no forno da história. O seu núcleo dirigente hesitou em diversos momentos da luta política. Trotski não negligenciou no trato dessa questão. (3) Por fim, Lênin exerceu uma tarefa exemplar não apenas com vistas ao rearmamento programático do partido, mas auscultando a movimentação da classe operária, para não deixar escapar o momento no qual o partido deveria encarregar-se de organizar a insurreição. Em síntese, essa conjunção entre situação objetiva (guerra e situação revolucionária), existência do partido bolchevique (mais do que uma doutrina, um sistema de educação revolucionária, como crê Trotski) e o papel do indivíduo na história (Lênin), com efeito, exerceu papel essencial no desfecho do outono russo.

Eis o curso típico da Revolução de Outubro. Não há como não ver nele uma questão inescapável: o olhar arguto de uma personagem que soube tirar dos acontecimentos que viveu as conclusões mais vivas e capazes de interessar aos que, vivendo noutro tempo, se veem diante da contingência de entendê-los e analisá-los. Em As lições de outubro, Trotski nos oferece uma primeira leitura dessa experiência peculiar da história do século XX. Essa leitura, contudo, pode servir apenas de pretexto para que o leitor e o crítico busquem o necessário aprofundamento das questões que, de maneira quase sumária, estão tratadas no livro. Decorre disso, a conveniência de tomarmos nas mãos um segundo texto do autor: História da revolução russa.

\begin{tabular}{|l|l|l|l|l|}
\cline { 2 - 4 } & Ano 8 & n. 14 & Janeiro - Julho 2019 & p. $264-277$ \\
\hline
\end{tabular}


No último livro, Trotski decorre longamente sobre o processo revolucionário, a datar de fevereiro e se estendendo até a vitória da Revolução de Outubro. Interessa-nos aqui, antes de tudo, a parte do livro que se prolonga do capítulo 34 (as massas sob ataque) até o capítulo 47 (o congresso da ditadura soviética) mais a conclusão. No caso do capítulo 34, Trotski desenvolve um raciocínio que já pode ser antevisto em As lições de outubro. Num raciocínio oposto a certo marxismo mecanicista (que só enxerga as premissas objetivas), ele escreve que:

As causas imediatas dos eventos de uma revolução são as mudanças na consciência das classes em luta. As relações materiais da sociedade apenas definem o canal dentro do qual estes processos acontecem. (TROTSKI, 2007, p. 693).

A virtude bolchevique, em larga medida, se mostrou na capacidade de recolher impressões cada vez mais precisas das mudanças que se processavam na consciência das classes em luta. Isso expresso, aqui se tem a base sobre a qual se modificou a tática bolchevique ao longo dos meses que precederam a insurreição vitoriosa. Nesse período, os bolcheviques só aumentaram sua força de atração, e nesse processo, nunca trataram com descaso a experiência independente das massas. Esse segundo elemento, de certo modo, ajuda a explicar o primeiro. Nessa perspectiva, as experiências de vida das massas, em última instância, deram convicção a Lênin e aos bolcheviques - minoritários na superestrutura - de que sua tática insurrecional era correta. Em suma, esse enlace do partido com o proletariado é determinante no curso dos acontecimentos e explica como seus 240 mil membros se mostraram capazes de arrastar atrás de si dezenas de milhões de homens e mulheres a uma conquista tão admirável.

Mas, não faltou flexibilidade tática aos leninistas para trazer para o lado da revolução, por exemplo, milhões de camponeses que, em tempo algum, ficaram ao alcance da influência bolchevique. A aliança com a esquerda dos socialistas revolucionários e a aceitação de seu programa agrário são provas palpáveis da agilidade política bolchevique. Nessa tática, era fundamental estar com os camponeses - maioria absoluta do povo russo. A respeito do campesinato, Trotski enfatizava que "A civilização transformou o campesinato em seu animal de carga. A burguesia, em longo prazo, apenas mudou a forma da cangalha" (TROTSKI, 2007, p. 785). Partindo desse fundamento histórico, os bolcheviques levantaram a necessidade da aliança dos trabalhadores urbanos com o campesinato pobre como condição necessária para emancipação de ambos. O partido do proletariado não havia de prescindir do concurso dos camponeses. Essa aritmética era imprescindível para revolução. E, assim, deu-se em 1917.

\begin{tabular}{|l|l|l|l|l|}
\cline { 2 - 4 } & Ano 8 & n. 14 & Janeiro - Julho 2019 & p. $264-277$ \\
\hline
\end{tabular}


Além da ligação com as massas urbanas e da aliança com os camponeses, os bolcheviques se apoiaram numa sólida argamassa teórica. Trotski não passou ao largo dessa questão. Ele discorreu sobre esse tema, diversas vezes, ao longo do livro e, a esse respeito, há passagens que são emblemáticas, como a que reproduzimos abaixo:

\footnotetext{
Uma época de poderosos levantes sociais não dá espaço para charlatães. Aqui a experiência histórica, mesmo iluminada pela intuição, não é suficiente. Aqui, deve-se ter uma doutrina sintética compreendendo as interações das principais forças históricas. Deve-se ter um método materialista que permita descobrir, por trás de sombras móveis de programas e palavras de ordem, o movimento real das classes da sociedade. (TROTSKI, 2007, p. 936).
}

Nota-se que a teoria se embebe do movimento real das classes da sociedade. Logo, não é um todo amorfo e desconectado. Se em condições de rotina, a teoria como teoria sobrevive, e até se estende, em tempos de "poderosos levantes sociais", ela só sobrevive e se estende em suas múltiplas relações com as principais forças históricas. Eis o conteúdo mais profundo do marxismo que nutria o partido bolchevique. Nesse quadro, o seu método materialista se mostrou vital para os que não só desejavam entender como funcionava a sociedade, mas como era possível transformá-la. Era o caso de Lênin, de Trotski e dos bolcheviques. No mais,

\footnotetext{
Graças a uma favorável combinação das condições históricas, domésticas e internacionais, o proletariado russo foi encabeçado por um partido de extraordinária clarividência política e têmpera revolucionária sem exemplo. Apenas isso permitiu a uma classe jovem e pouco numerosa realizar uma tarefa histórica de proporções sem precedentes. (TROTSKI, 2007, p. 937).
}

Cremos que essa citação sintetiza admiravelmente as principais conclusões que Trotski apresenta ao longo dos capítulos que servem de fundamento e inspiração a esse momento da análise. Evidentemente, o texto de Davidovitch é mais nuançado, e nos limites de um artigo como este, a tendência é vê-lo, de alguma maneira, empobrecido. Logo, os que tenham a pretensão de criticá-lo, abstenham-se dessa tarefa, ou a transfiram para o autor deste artigo. Por fim, quanto aos que se limitam a criticar a ação bolchevique pela conquista do poder, Trotski lembra simplesmente que ela "foi a mais popular insurreição de massas de toda a História" (idem, p. 984). De certa maneira, esse intervalo de pouco mais de um século e as controvérsias que dele se desprendem, por si mesmo, já certifica a conveniência do juízo histórico de Leon Trotski.

\begin{tabular}{|l|l|l|l|l|}
\cline { 2 - 5 } & Ano 8 & n. 14 & Janeiro - Julho 2019 & p. $264-277$ \\
\hline
\end{tabular}




\section{Notas conclusivas: Trotski é contemporâneo do século XXI}

Quando bate na porta da história um pouco mais de cem anos da Revolução Russa, de fato, convém ao historiador girar a maçaneta e deixá-la entrar. Eis a atitude que adotamos neste artigo, no qual nos fundamentamos em uma questão específica - o lugar teórico e militante de Trotski nos acontecimentos de 1917 - para tratar do problema com o máximo de amplitude.

O que é certo, em todo caso, é que Leon Trotski tem seu nome ligado ao mais célebre e memorável acontecimento do século XX: a Revolução Russa. Na prática, Trotski destinou à revolução o melhor de suas forças físicas e mentais, rememorou o seu itinerário por meio de uma análise fascinante que, mesmo no transcurso de um século do fato histórico em questão, não há como a memória a respeito desse homem e da história com a qual ele se confunde, de fato, ser esquecida, dobrada ou estilhaçada. Ademais, a retomada de seus textos acerca da revolução é sempre um bafejo generoso para todo aquele que se sente revitalizado diante de qualquer análise em que imaginação intelectual e rigor analítico se cruzam como partes constituintes de um mesmo objeto. Por fim, segue válida a sua reflexão de que, efetivamente,

(...) o historiador não cometerá erros se disser que, em 25 de outubro, não apenas a luz elétrica foi cortada da tipografia governamental, mas uma importante página se abriu na História da Humanidade. (TROTSKI, 2007, p. 1020).

Página de um livro por natureza inconcluso, o qual deve ser escrito pelas massas exploradas e oprimidas. Nessa escrita, diversa e multicor, a pena do revolucionário bolchevique, ucraniano e judeu pode contribuir com os contornos da luta emancipatória pelo socialismo.

De acordo com Coggiola (1995), foi depois de sua morte, orquestrada pela burocracia stalinista, que o pensamento de Trotski esculpido pela revolução russa, teve, em suas linhas estratégicas, sua confirmação espetacular: 1) nos países atrasados, a revolução só foi vitoriosa naqueles em que houve um transcrescimento da revolução democrática em revolução socialista, com a recusa de todo compromisso estratégico com a burguesia e o imperialismo (Cuba e Vietnã, por exemplo); 2) contra os teóricos stalinistas, neostalinistas, socialdemocratas ou "terceiro-mundistas", a revolução proletária provou a sua vigência objetiva nas metrópoles imperialistas: na Europa Ocidental no imediato pós-guerra foram necessárias inéditas concessões da burguesia às massas para contê-la, e, também, na mesma região no período que vai do maio francês de 1968 até à revolução portuguesa de 1974-1975; 3) as frentes populares provaram ser uma política de derrota, conduzindo ao aborto da revolução e, nos casos extremos

\begin{tabular}{|l|l|l|l|l|}
\cline { 2 - 5 } & Ano 8 & n. 14 & Janeiro - Julho 2019 & p. $264-277$ \\
\hline
\end{tabular}


à vitória fascista: Europa Ocidental no pós-guerra, Portugal 1974-1975, Chile 1970-1973, Nicarágua na década de 1980;4) Na ausência de uma direção revolucionária mundial os processos revolucionários abortaram, ou quando vitoriosos nacionalmente, não deram início à revolução mundial ou a sua extensão continental, levando-as ao isolamento e à degeneração; 5) a burocratização dos Estados operários na URSS, Europa Oriental e Ásia conduziu essas sociedades a um completo impasse.

Essa breve síntese do pensamento trotskista apenas indica que o historiador e militante da Revolução Socialista Russa abre-nos uma porta rica de possibilidades e faz-nos um convite: a vitória é possível, Outubro está presente!

\section{Referências}

BROUÉ, Pierre. O partido bolchevique. São Paulo: Sundermann, 2007.

Instituto de Marxismo-Leninismo anexo ao CC do PCUS. Biografia de V. I. Lénine. Lisboa; 276 Moscou: Edições “Avante!”; Edições Progresso, 1984.

COGGIOLA, Osvaldo. Prefácio. In: MANDEL, Ernest. Trotsky como alternativa. São Paulo: Xamã, 1995.

LÉNINE, V. I. Sobre as tarefas do proletariado na presente revolução. In: LÉNINE, V. I. Obras escolhidas em três tomos, 2. Lisboa; Moscovo: Edições “Avante!”; Edições Progresso, 1978.

LÊNIN, V. I. Últimos escritos e diário das secretarias. São Paulo: Sundermann, 2012.

LUXEMBURGO, Rosa. Textos escolhidos, v. II, Isabel Loureiro (Org.). São Paulo: Editora da Unesp, 2011.

REED, John. 10 dias que abalaram o mundo. Porto Alegre: L\&PM, 2002.

SERGE, Victor. O ano I da Revolução Russa. São Paulo: Boitempo, 2007.

TROTSKI, Leon. As lições de outubro. Lisboa: Edições Antídoto, 1979.

\begin{tabular}{|l|l|l|l|l|}
\cline { 2 - 4 } & Ano 8 & n. 14 & Janeiro - Julho 2019 & p. $264-277$ \\
\hline
\end{tabular}


História da revolução russa, tomo II, partes 2 e 3. São Paulo: Sundermann, 2007.

\begin{tabular}{|l|l|l|l|l|}
\hline Q & Ano 8 & n. 14 & Janeiro - Julho 2019 & p. 264 - 277 \\
\hline
\end{tabular}

